\title{
EDUCATIONAL RESEARCH: MATERIAL CULTURE AND ITS REPRESENTATION,
}

por Paul Smeyers y Marc Depaepe (eds.). Cham: Springer International Publishing, 2014, 219 páginas. ISBN: $9783319030821 ; 9783319030838$.

Plantearnos una revisión de los estudios realizados en historia de la educación con fundamentos estéticos —sean estos artísticos, literarios, de sensibilidad, etc. - nos lleva a considerar las obras de detalles que se han realizado, o estudios específicos, así como aquellas de planteamientos panorámicos que se están justamente editando en estos momentos. La obra que aquí reseñamos, Educational Research: material culture and its representation, pertenece a esta última categoría integrando en su desarrollo diferentes aspectos puntuales que dan cobertura al estudio aplicado. El grupo promotor de la obra cuenta con una larga tradición en estudios de concreción que integran planteamientos epistemológicos de estética, fuentes de estudio visuales (gráficas, filmes, etc.) y desarrollos de proceso de las metodologías estéticas. ${ }^{1}$ No es de extrañar pues que el evento, celebrado en 2012 bajo el nombre de Research Community, que originariamente tenía como centro de interés la materialidad en la historia de la educación, diera lugar a la edición de un libro de referencia para los estudios que tienen como base o despliegue la estética.

A pesar de la consideración de los autores sobre su intención de plantear un libro que amalgame diferentes artículos con aspectos, aproximaciones y contextos de investigación entendidos "como calidoscopios» sobre la cultura material, en el libro hallamos una sistematización de aquellos lugares y recorridos por los que la estética va filtrándose en las investigaciones sobre historia de la educación.

\footnotetext{
${ }^{1}$ No podemos dejar de referenciar aquí el congreso: 1998 ISCHE 20 Kortrijk, Belgium. The Challenge of the Visual in the History of Education en el que se asumió el reto planteado por María del Mar del Pozo de atender a las imágenes como fuente histórica.
} 
La propia presentación del libro, realizada en el capítulo n. 1, «On the Tangible Material Culture of Child-Rearing, Education and Educational Research», elaborada por los editores Paul Smeyers y Marc Depaepe, es ya en sí misma un alegato de apertura de horizontes que se aproxima más a los desarrollos de la filosofía de la estética del conocimiento que a una revisión disciplinar de la historia material de la cultura. Algunos de los términos con los que se abre la discusión así nos lo indican: la configuración del sujeto moderno, las relaciones que se establecen entre humanidad, naturaleza y objetualidades, la dicotomía entre lo mágico, el destino y la predestinación o las posibilidades de autoeducación, emancipación o realización del individuo. Sin lugar a dudas, ellos nos evocan a los ecos de la Bildungsroman, de la fenomenología y de las teorías de la recepción.

La conexión con la fenomenología y las teorías de la recepción puede apreciarse ya en el primer estudio presentado, que es el correspondiente a «Valorising the Cultural heritage of the School Desk Through Historical Research» de Marc Depaepe, Frank Simon y Pieter Verstraete. El esquema de análisis convergente que proponen para volverse a acercar a los pupitres incluye varios de los aspectos —en ocasiones, direcciones de investigación- que tienen su desarrollo en las investigaciones estéticas de la historia de la educación. Este análisis se inicia investigando cómo se ha ido construyendo la iconografía del aula, y analizando cómo ésta ha derivado en una metáfora normalizada. Continua con la aproximación de cómo las ideaciones que subyacen a los proyectos pedagógicos y comerciales dan vida - o la imposibilitan — a determinadas invenciones materiales. Da cuenta de una historia vital de los objetos, en la que irrumpen las expectativas y los imaginarios, así como la fuerza de la liturgia que son, según los autores, algunos de los aspectos clave para relatar una historia de la educación dinámica escrita y en constante reconstrucción en los museos que dan voz a las historias pasadas.

Dialogando con las diferentes aportaciones que van apareciendo a lo largo de los capítulos, podemos considerar que esta obra contribuye a elaborar una propuesta que nos permita avanzar en formas de investigar desde la estética, con las artes y referencias visuales. Una propuesta que, aunque reconoce las aportaciones de las investigaciones con base en el análisis textual y lingüístico, atiende a las especificidades derivadas de 
este ámbito. A continuación, detallo algunos de los elementos que me parecen sobresalir en este panorama, y que he desordenado de su lugar inicial para intentar configurar una topografía que permita desarrollar una investigación con las bases que los autores y autoras introducen, adaptando posiciones, lenguajes y formas a las investigaciones estéticas de la historia de la educación.

Como inicio, recojo dos de las ideas expuestas en el capítulo 8, elaborado por Lynn Fendler, «The Ethics of Materiality: Some Insights from Non-representational Theory». Estas son las correspondientes al lugar donde nos situamos en la investigación y al primer posicionamiento ante la ordenación-categorización de los elementos de estudio con la que organizamos nuestro increpar a las fuentes.

En este texto, la autora nos recuerda la necesidad de ubicarse ante la investigación histórica desde una posición que implique «el querer estar presente» más que buscar representar una realidad ya acontecida. ${ }^{2}$ A través de sus incursiones en la geografía y en la cartografía, y a partir de un intenso diálogo crítico con Wittgenstein, así como con el estructuralismo lingüístico, Fendler incorpora la necesidad en historia de la educación, no de establecer otra verdad, sino de presentar una recuperación de la experiencia inmanente, y por ello existente, que nos permita avanzar en nuestro ser actual. Para ello, considera relevante romper con las dicotomías instaladas en la lógica de investigación de subjetivismo-objetivismo, para entender que todo proceso de cognición actual y pasado contiene elementos de reproducción, de agencia, de creación y, por tanto, nada es ni tan particular o singular, ni tan común o universal, ni tan estructural, institucional o individual, y todo es una amalgama de proyecciones, deseos, realidades y hechos. Esta operación que propone la autora conlleva consigo dos anclajes estéticos: el de pensar desde la unidad parcial, a la que ya dio nombre Hölderlin, y el de reubicar las categorizaciones y convenciones preestablecidas sobre la fiabilidad de las fuentes para poder decidir en cada momento qué fuentes nos están interpelando, desde dónde y hacia dónde. Lo cual implica, utilizando su

\footnotetext{
${ }^{2}$ Sobre el tema realizan un desarrollo posterior Lynn Fendler y Paul Smeyers en «Focusing on presentation instead of representation: perspectives on representational and non-representational language games for educational history and theory», Paedagogica Historica, 51 (6), (2015): 691-701, DOI: 10.1080/00309230.2015.1058829.
} 
lenguaje, pensar la historia desde una perspectiva estratégica ${ }^{3}$ - a la que yo denominaría perspectiva poética, apropiándome de la formulación de María Zambrano- y moverse en confianza - aunque no necesariamente aplaudiéndolo o dando fe de su total veracidad- con lo que escribió el alumnado, dibujaron los niños y niñas o los artistas, filmaron los directores, escribieron los pedagogos, etc.

En la misma línea, pero argumentando desde la historia cultural, Karim Priem en "Visual, Literary, and Numerical Perspectives on Education: Materiality, Presence, and Interpretation» se pregunta por cómo podemos interrogarnos por la presencia de la materialidad desde la matriz de tiempo, espacio, función, forma e interacción; en cómo la materialidad evidenciada, más que interpretada, nos da códigos emocionales que derivan del contexto de origen, y cómo, interactuar con los mismos, nos permite entrelazar sino historias, sí narraciones. En su caso, se postula desde una óptica analítica que recupera las aportaciones de la etnografía descriptiva, por un lado, y, por otro, las corrientes interpretativas que dan cuenta de la importancia de los objetos de la vecindad, producida por voluntad de quienes crearon los objetos, los vendieron, los utilizaron o los recuperaron. Es en esta segunda instancia que se nos abre la pregunta sobre cómo y por qué desde el presente pasado o desde el presente actual creamos objetos y libros vecinos, o cómo y por qué decidimos atender a lo que Warburg denominaba, y aplicaba en su biblioteca, la «ley del mejor vecino». ${ }^{4} \mathrm{El}$ suyo es, pues, un camino que nos invita a seguir como método de estudio el ir «de la palabra a la imagen», ${ }^{5}$ y recorrer posteriormente el proceso al revés, para concluir en la construcción imaginada —si se quiere, de índole profundamente cuantitativa de los números de cualificación estadística-. A nivel de investigación de la historia de la educación con posicionamientos y fuentes estéticas, Priem nos invita a pensar sobre las razones del lugar en el que disponemos los materiales, con lo que ello conlleva de revisar de manera continua los problemas que nos preocupan de manera profunda y no siempre diáfana. Cuestión que nos permite alejarnos de la conservadora pregunta, cuando se convierte

\footnotetext{
${ }^{3}$ Lynn Fendler, «The upside of presentism», Paedagogica Historica, 44 (6), (2008): 677-690, DOI: $10.1080 / 00309230802486150$.

${ }^{4}$ Salvatore Settis, Warburg Continuatus. Descripción de una biblioteca (Barcelona - Madrid: La Central - Museo Nacional Centro de Arte Reina Sofía, 2010), 8.

${ }^{5}$ Settis, Warburg Continuatus, 13.
} 
en única, sobre la funcionalidad de los modelos, prácticas y materiales, tan criticada en el capítulo 5 elaborado por Sophie Ward «Education and the "New Totalitarianism»: How Standards for Reporting on Empirical Studies of Education Limit the Scope of Academic Research and Communication».

Podemos considerar que este capítulo de Priem abre las aportaciones sobre aspectos parciales de la investigación, bien sea por atender a los materiales de estudio, y cómo estos condicionan nuestra investigación —capítulo 6 de Naomi Hodgson «Materials That Shape Researchers»—, o cómo la materialidad de la investigación, en su sentido más peyorativo, está condicionando un horizonte de investigaciones y citaciones «al uso» que puede hallarse en los capítulos 9 de Richard Smith, «Mud and Hair: An Essay on the Conditions of Educational Research»; 12 de Paul Standish, "Signs of the Times: Iconography of a New Education»; 11 de Kathleen Coessens, Karen François y Jean Paul Van Bendegem, «Olympification Versus Aesthetization: The Appeal of Mathematics Outside the Classroom»; y 13 de Nicholas C. Burbules, «The Paradigmatic Differences Between Name/Date and Footnote Styles of Citation». Más allá de los temas que los citados capítulos presentan, existe una corriente subterránea en los mismos con la intención de identificar aquellos elementos circunstanciales que están vaciando de profundidad algunas investigaciones a tenor de, ya no una comprensión limitada de la metodología —como sí destaca Paul Smeyers en su capítulo 7, «The Tractarian Template in the Representation of Educational Research: Can We Ever Depart from the Picture of Logical Empiricism?»-, sino de una nueva presentación iconográfica de la investigación que tiene sus cánones, sus lenguajes y sus gramáticas.

Diferentes propuestas intentan superar esta versión limitada de la investigación en historia de la educación que los autores citados denuncian. Dos de ellas se desarrollan desde las artes, bien en tanto que es su tema de investigación, bien porque se traza un proceso de investigación afianzado desde la práctica artística. Concretamente, nos referimos en el primer caso al estudio de Jeroen J. H. Dekker presentado en el capítulo 3: "Mirrors of Reality? Material Culture, Historical Sensation, and the Significance of Images for Research into Long-Term Educational Process», sobre la necesidad de atender a las claves y las trazas que se insinúan en 
las fuentes consideradas débiles, en el que nos propone recuperar la intencionalidad performativa original de las escenas familiares pintadas en cuadros y libros emblemáticos, desde la óptica de un espejismo creado a propósito. Sin voluntad de poder llegar a interpretar lo que se buscaba o quería en su totalidad, el suyo es un ejemplo de cómo indagar en los imaginarios educativos —en sus palabras, ambiciones educativas-. $\mathrm{Y}$ en el segundo, al trabajo conjunto de Maureen K. Michael and Ian Munday, «Material and Aesthetic Tensions Within Arts-Based Educational Research: Drawing Woodpaths», en el que se abre un diálogo que retorna a los planteamientos de Priem sobre la estética de las relaciones para presentar artísticamente y representar estéticamente las cosas de la práctica, ya no como entidades individuales, sino como entidades en constante relación. En la práctica, una conversación que anticipa el sentido del capítulo 14 desarrollado por David Bridges, "Conversation- In the Construction and Representation of Research».

En resumen, la lectura de este libro nos invita a pensar la investigación desde una actitud, posicionamiento, proceso y comunicación que nos devuelve a una práctica investigadora actualizada de los posicionamientos de la estética elaborada desde las artes y casi siempre en respuesta a los discursos predominantes de cada período histórico.

Pilar Prat y Eulàlia Collelldemont Universidad de Vic-Universidad Central de Cataluña Pilar.prat@uvic.cat; eulalia@uvic.cat 